\title{
Neutrophil/lymphocyte ratio is associated with right ventricular dysfunction in patients with acute inferior ST-segment elevation myocardial infarction
}

\author{
Barıs Yaylak ${ }^{1}$, Huseyin Ede ${ }^{2}$, Erkan Baysal ${ }^{1}$, Bernas Altıntas ${ }^{1}$, Sukru Akyuz ${ }^{3}$, \\ Utkan Sevuk $^{4}$, Guney Erdoğan ${ }^{5}$, Nuri Comert ${ }^{6}$, Ender Ozgun Cakmak ${ }^{7}$, \\ Rojhat Altındag $^{1}, Z_{\text {Zulkuf Karahan }}{ }^{1}$, Onder Bilge ${ }^{1}$, Kemal Cevik ${ }^{1}$
}

${ }^{1}$ Department of Cardiology, Diyarbakir Gazi Yasargil Training and Research Hospital, Diyarbakır, Turkey

${ }^{2}$ Department of Cardiology, Bozok University School of Medicine, Yozgat, Turkey

${ }^{3}$ Department of Cardiology, Siyami Ersek Thoracic and Cardiovascular Surgery

Training and Research Hospital, Istanbul, Turkey

${ }^{4}$ Department of Cardiovascular Surgery, Diyarbakir Gazi Yasargil Training and Research Hospital, Diyarbakır, Turkey

${ }^{5}$ Department of Cardiology, Ordu State Hospital, Ordu, Turkey

${ }^{6}$ Department of Cardiology, Antalya Memorial Hospital, Antalya,Turkey

${ }^{7}$ Department of Cardiology, Kosuyolu Training and Research Hospital, Istanbul, Turkey

\begin{abstract}
Background: Acute inferior ST-segment elevation myocardial infarction (STEMI) is associated with increased in-hospital morbidity and mortality particularly among patients with coexisting right ventricular (RV) involvement. High neutrophil to lymphocyte ratio (NLR) is an independent predictor of major adverse cardiac events and mortality in patients with myocardial infarction. This study evaluated the relationship between the NLR and RV dysfunction (RVD) in patients with inferior STEMI who underwent primary percutaneous coronary intervention (PCI).
\end{abstract}

Methods: A total of 213 subjects with inferior STEMI were divided into two groups according to the presence of $R V D$. The groups were compared according to NLR and receiver operating characteristic (ROC) analysis was performed to access the predictability of NLR on having RVD.

Results: The NLR was significantly higher in the group with RVD compared to that without $R V D(p<0.001)$. In ROC analysis, NLR > 3.5 predicted RVD with sensitivity of $83 \%$ and specificity of 55\%. In a multivariate regression analysis, NLR remained an independent predictor of RVD (OR 1.55, 95\% CI 1.285-1.750, $p<0.001)$.

Conclusions: NLR was an independent predictor of RVD in patients with inferior STEMI undergoing primary PCI. (Cardiol J 2016; 23, 1: 100-106)

Key words: neutrophil/lymphocyte ratio, inferior wall myocardial infarction, right ventricular dysfunction, primary percutaneous coronary intervention

Address for correspondence: Baris Yaylak, MD, Diyarbakir Gazi Yasargil Egitim ve Arastırma Hastanesi Ückuyular Mevkii, Yenisehir, Diyarbakır, Turkey, tel: +90 532 5036464, fax: +90 4122580070, e-mail: bryaylak@yahoo.com 


\section{Introduction}

Autopsy findings showed that right ventricular (RV) involvement is observed in up to $50 \%$ of patients with inferior ST-segment elevation myocardial infarction (STEMI) [1, 2]. Acute inferior STEMI is associated with increased in-hospital morbidity and mortality particularly among patients with coexisting RV involvement [3, 4]. However, long-term prognosis is generally good for those who survive the event.

Inflammation plays an important role in the pathogenesis and progression of the atherosclerosis $[5,6]$. The neutrophil to lymphocyte ratio (NLR) shows balance between neutrophil and lymphocyte levels and can be used as an indicator of systemic inflammation. High NLR is an independent predictor of major adverse cardiac events and mortality in patients with acute myocardial infarction (MI) [7]. Although predictive value of NLR in patients with STEMI is well known, the relationship between NLR and the inferior STEMI with RV dysfunction (RVD) has not been evaluated before. Therefore, the aim of the present study was to evaluate the association between the NLR and RV function among patients with inferior STEMI undergoing primary percutaneous coronary intervention (PCI).

\section{Methods}

\section{Patient population}

This prospective study was conducted between January 2012 and January 2015. A total of 213 subjects with inferior STEMI presented within $12 \mathrm{~h}$ from the symptom onset were included in the study. All patients were treated with primary PCI. Inferior STEMI was defined as ST-segment elevation $>1 \mathrm{~mm}$ in any two consecutive inferior leads. Right precordial electrocardiograms (V3R through V6R) were recorded immediately after admission to the emergency room. ST-segment elevation was measured $0.08 \mathrm{~s}$ after the $\mathrm{J}$ point in V4R. Three consecutive QRS complexes were measured with the PQ level used as the isoelectric line. All analyses were performed by a cardiologist blinded to the clinical data of the patient. By the help of electrocardiogram of each patient, the presence of ST-segment elevation $\geq 1 \mathrm{~mm}$ in lead V4R searched accordingly.

Exclusion criteria were treatment with fibrinolytics in the previous $24 \mathrm{~h}$, presence of active infection, chronic pulmonary disease, pulmonary hypertension, malignancy, end-stage liver disease, renal failure and past history of a systemic inflammatory process. Informed consent of each subject and approval of the Local Ethics Committee were obtained.

Angiographic variables were multivessel coronary artery disease, thrombolysis in myocardial infarction (TIMI) flow in main right coronary artery before primary PCI. The TIMI flow grades were assessed as previously described [8]. The site of occlusion of the right coronary artery was defined as proximal or distal based on the origin of the major ( $>1 \mathrm{~mm}$ in diameter) RV branch. The purpose of the primary PCI procedure was to obtain a residual stenosis of $<20 \%$ in the infarct-related artery by visual evaluation. A successful angiographic result was defined as residual stenosis $<20 \%$ associated with TIMI grade 2-3 flow. All patients received dual antiplatelet therapy with aspirin and clopidogrel $(600 \mathrm{mg})$ or ticagrelor $(180 \mathrm{mg})$ loading dose. Preprocedural anticoagulation consisted of intravenous unfractionated heparin $(70 \mathrm{IU} / \mathrm{kg}$ ) in all cases. PCI with stent implantation was performed according to current guidelines [9].

Patients underwent standard 2-dimensional echocardiography with a digital ultrasonic device system (iE33; Philips, Netherlands) immediately after PCI. RVD was defined according to the recommendations of American Society of Echocardiography [10]. Patients were divided into two groups: patients with normal RV function (TAPSE > 17) (group 1), and patients with RVD (TAPSE $\leq 17$ ) (group 2).

In all patients, blood samples were collected from antecubital vein at emergency room for laboratory analysis. Complete blood count (CBC) parameters were measured by an ABX Pentra DX 120 hematology analyzer immediately after sampling. Biochemical parameters were measured by the Roche Cobas Integra 800 (Roche diagnostic limited, Switzerland) and troponin-I was measured by an AQT 90 Flex immunoassay analyzer (Radiometer, Denmark).

\section{Statistical analysis}

Categorical variables were compared with $\chi^{2}$ or Fisher's exact test when appropriate. Continuous variables were presented as mean + standard deviation, whereas categorical variables as count and percentages. The Kolmogorov-Smirnov test was used to evaluate whether the distribution of continuous variables was normal. Continuous variables were compared with Student's t test or Mann-Whitney U test as appropriate. Receiver operating characteristic (ROC) curve was used to assign the sensitivity and specificity of NLR and the optimal cut-off value for predicting RVD in patients with inferior STEMI. Association of different variables with RVD was calculated in univariate 
Table 1. Baseline characteristics, electrocardiogaphic characteristics and in-hospital therapy.

\begin{tabular}{|c|c|c|c|}
\hline \multirow[t]{2}{*}{ Variable } & \multicolumn{2}{|c|}{ Right ventricular dysfunction } & \multirow[t]{2}{*}{$\mathbf{P}$} \\
\hline & Absent $(n=120)$ & Present $(n=93)$ & \\
\hline Age [years] & $56.5 \pm 10.2$ & $55.8 \pm 10.9$ & 0.62 \\
\hline Male & $94(78.3 \%)$ & $76(81.7 \%)$ & 0.54 \\
\hline Hypertension & $66(55 \%)$ & $53(57 \%)$ & 0.77 \\
\hline Diabetes mellitus & $29(24.2 \%)$ & $23(24.7 \%)$ & 0.92 \\
\hline Smoke & $67(56 \%)$ & $57(61 \%)$ & 0.33 \\
\hline Body mass index $\left[\mathrm{kg} / \mathrm{m}^{2}\right]$ & $25.2 \pm 3.1$ & $25.7 \pm 3.0$ & 0.20 \\
\hline Family history of CAD & $25(20.8 \%)$ & $20(21.5 \%)$ & 0.90 \\
\hline Previous MI & $24(20 \%)$ & $17(18.3 \%)$ & 0.75 \\
\hline Previous $\mathrm{PCl}$ & $11(9.2 \%)$ & $10(10.8 \%)$ & 0.70 \\
\hline Previous CABG & $3(2.5 \%)$ & $4(4.3 \%)$ & 0.50 \\
\hline $\mathrm{GFR}\left[\mathrm{mL} / \mathrm{min} / 1.73 \mathrm{~m}^{2}\right]$ & $83.1 \pm 4.6$ & $82.4 \pm 4.4$ & 0.28 \\
\hline Heart rate $[\mathrm{bpm}]$ & $72.3 \pm 15.6$ & $70.3 \pm 18.9$ & 0.60 \\
\hline Glucose on admission & $161 \pm 76.7$ & $170 \pm 79.4$ & 0.15 \\
\hline Peak troponin I [ng/dL] & $6.1 \pm 2.3$ & $6.7 \pm 2.7$ & 0.04 \\
\hline Triglyceride [ng/dL] & $159.0 \pm 83.1$ & $167.3 \pm 78.5$ & 0.30 \\
\hline Total cholesterol [mg/dL] & $178 \pm 43.0$ & $185.6 \pm 42.9$ & 0.25 \\
\hline Low-density lipoprotein [mg/dL] & $119.3 \pm 33.4$ & $124.6 \pm 32.1$ & 0.18 \\
\hline High-density lipoprotein [mg/dL] & $35.8 \pm 9.2$ & $36.0 \pm 9.3$ & 0.80 \\
\hline Hemoglobin $[\mathrm{g} / \mathrm{L}]$ & $14.0 \pm 2.3$ & $14.7 \pm 2.9$ & 0.60 \\
\hline Platelet $\left[/ \mathrm{mm}^{3}\right]$ & $260.5 \pm 75.0$ & $264.0 \pm 60.5$ & 0.20 \\
\hline White blood cell count $\left[10^{3} / \mu \mathrm{L}\right]$ & $10.2 \pm 3.3$ & $12.8 \pm 3.4$ & 0.007 \\
\hline Neutrophils $\left[10^{3} / \mu \mathrm{L}\right]$ & $7.8 \pm 3.2$ & $10.7 \pm 3.2$ & 0.003 \\
\hline Lymphocytes $\left[10^{3} / \mu \mathrm{L}\right]$ & $2.4 \pm 0.9$ & $2.0 \pm 0.6$ & 0.02 \\
\hline Neutrophil/lymphocyte ratio & $3.9 \pm 2.3$ & $6.0 \pm 2.8$ & $<0.001$ \\
\hline Time from symptoms onset to $\mathrm{PCl}[\mathrm{h}]$ & $6.0 \pm 1.5$ & $6.5 \pm 1.2$ & 0.04 \\
\hline Door to balloon time [min] & $65 \pm 12.5$ & $65.3 \pm 13.7$ & 0.40 \\
\hline V4R ST-elevation & $17(14.2 \%)$ & $76(81.7 \%)$ & $<0.001$ \\
\hline \multicolumn{4}{|l|}{ In-hospital therapy: } \\
\hline Aspirin & $115(96 \%)$ & $90(97 \%)$ & 0.72 \\
\hline Beta-blocker & $72(60 \%)$ & $56(60 \%)$ & 0.97 \\
\hline ACEI/AT-1 antagonist & $71(60 \%)$ & $52(56 \%)$ & 0.63 \\
\hline Clopidogrel & $109(90.8 \%)$ & $82(88.2 \%)$ & 0.53 \\
\hline Ticagrelor & $11(9.2 \%)$ & $11(11.8 \%)$ & 0.52 \\
\hline Statin & $115(95.8 \%)$ & $90(96.8 \%)$ & 0.72 \\
\hline Glycoprotein Ilb/IIla inhibitor & $17(14.1 \%)$ & $15(16.2 \%)$ & 0.48 \\
\hline
\end{tabular}

Data are expressed as mean \pm standard deviation for normally distributed data or count (percentage) for categorical variables; CAD — coronary artery disease; $\mathrm{MI}$ - myocardial infarction; $\mathrm{PCl}$ - percutaneous coronary intervention; CABG - coronary artery bypass grafting; GFR - glomerular filtration rate; ACEI — angiotensin converting enzyme inhibitor

analysis. Backward stepwise logistic regression analysis was used to assess independent predictors of RVD. A p value $<0.05$ was considered statistically significant. All statistical studies were carried out using Statistical Package for Social Sciences software (SPSS 18.0 for Windows, SPSS Inc., Chicago, Illinois).

\section{Results}

Baseline characteristics are presented in Table 1 . There were no statistically significant differences in respect to demographic, baseline clinical values, coronary risk factors and in-hospital therapy between the groups. Peak troponin I was 
Table 2. Angiographic characteristics.

\begin{tabular}{|c|c|c|c|}
\hline \multirow[t]{2}{*}{ Variable } & \multicolumn{2}{|c|}{ Right ventricular dysfunction } & \multirow[t]{2}{*}{$\mathbf{P}$} \\
\hline & Absent $(n=120)$ & Present $(n=93)$ & \\
\hline Number of diseased coronary arteries: & & & 0.04 \\
\hline 1 & $54(45 \%)$ & $55(60 \%)$ & \\
\hline$>1$ & $66(55 \%)$ & $38(41 \%)$ & \\
\hline Coronary lesion location at RCA: & & & $<0.001$ \\
\hline Proximal & $32(27 \%)$ & $74(80 \%)$ & \\
\hline Distal & $88(73 \%)$ & $19(20 \%)$ & \\
\hline TIMI flow before $\mathrm{PCl}$ in main RCA: & & & 0.43 \\
\hline TIMI 0 & $97(80.8 \%)$ & $79(84.9 \%)$ & \\
\hline TIMI 1 & $23(19.2 \%)$ & $14(15.15)$ & \\
\hline TIMI flow after $\mathrm{PCl}$ in main RCA: & & & 0.27 \\
\hline Unsuccessful & $12(10 \%)$ & $14(15 \%)$ & \\
\hline Successful & $108(90 \%)$ & $79(85 \%)$ & \\
\hline
\end{tabular}

$\mathrm{RCA}$ - right coronary artery; $\mathrm{PCl}$ — percutaneous coronary intervention; $\mathrm{TIMI}$ — thrombolysis in myocardial infarction

significantly higher in patients with RVD. Average white blood cell count, neutrophils count and NLR were significantly higher while lymphocytes count were significantly lower in patients with RVD. Time from symptoms onset to PCI was significantly higher in patients with RVD. We performed further analyses and clustered time durations as follows: $<3 \mathrm{~h}, 3-6 \mathrm{~h}$ and $>6 \mathrm{~h}$. Fifteen percent of the patients with RVD applied within first $3 \mathrm{~h}, 65 \%$ within $3-6 \mathrm{~h}$ and $20 \%$ within $6-12 \mathrm{~h}$ of symptom onset while $60 \%$ of the patients without RVD applied within first 3 h, 25\% within 3-6 h and 15\% within $6-12 \mathrm{~h}$ of symptom onset. There was a significant difference between the groups in respect to frequency of these time durations. A larger proportion of the patients with ST-elevation in lead V4R was observed in patients with RVD.

Table 2 summarized angiographic results of the patients. A larger proportion of the patients with multivessel coronary disease was observed in patients without RVD. Coronary lesion location was significantly different between the two groups. A large proportion of patients with proximal lesion was observed in patients with RVD. There was no significant difference in TIMI flow before and after PCI between the two groups.

Echocardiographic findings are presented in Table 3. Mean tricuspid annular plane systolic excursion was significantly lower in patients with RVD. Consistently, RV fractional area changes were significantly lower in patients with RVD.
ROC curve of NLR for predicting RVD is shown in Figure 1. NLR of $>3.5$ was found to predict RVD with sensitivity of $83 \%$ and specificity of $55 \%$.

Some variables associated with RVD were significantly different between the two groups; and NLR was found to be an independent predictor of RVD in the multivariable logistic regression analysis (odds ratio 1.55, 95\% confidence interval 1.285-1.750, $\mathrm{p}<0.001$; Table 4).

\section{Discussion}

Several factors involve impairment of perfusion at tissue level after STEMI. These are white blood cell and platelet accumulation in capillaries, inflammation-driven complex neutrophil and platelet interactions, reactive oxygen radicals, distal thrombus embolization, and endothelial dysfunction due to ischemia and reperfusion injury. Inflammation has a substantial contribution to this process. It has also a negative effect on myocardial function. Response of white blood cells to different inflammatory triggers leads to secretion of proinflammatory cytokines such as tumor necrosis factor-alpha, interleukin-6, and C-reactive protein. By the effects of these cytokines, contractile function of myocardium may decrease [11, 12]. Active neutrophils also secrete several proteolytic enzymes such as myeloperoxidase, acid phosphatase, and elastase which help destroying tissue structure, and neutrophil-driven microvascular obstruction 
Table 3. Echocardiographic characteristics.

\begin{tabular}{|c|c|c|c|}
\hline \multirow[t]{2}{*}{ Variable } & \multicolumn{2}{|c|}{ Right ventricular dysfunction } & \multirow[t]{2}{*}{$\mathbf{P}$} \\
\hline & Absent $(n=120)$ & Present $(n=93)$ & \\
\hline Left ventricular end-systolic volume [mL] & $55.5 \pm 8.8$ & $56.7 \pm 10.4$ & 0.35 \\
\hline Left ventricular end-diastolic volume [mL] & $96.2 \pm 11.2$ & $97.5 \pm 11.3$ & 0.75 \\
\hline Left ventricular ejection fraction [\%] & $44.9 \pm 2.6$ & $44.2 \pm 3.5$ & 0.07 \\
\hline E/A ratio & $1.1 \pm 0.2$ & $1.0 \pm 0.2$ & 0.23 \\
\hline $\mathrm{E} / \mathrm{e}^{\prime}$ ratio & $9.8 \pm 3.3$ & $9.8 \pm 2.6$ & 0.65 \\
\hline Moderate or severe mitral regurgitation & $12(9.5 \%)$ & $10(11.5 \%)$ & 0.65 \\
\hline Moderate or severe tricuspid regurgitation & $12(9.5 \%)$ & $15(17.2 \%)$ & 0.13 \\
\hline Right ventricular end-systolic volume [mL] & $23.3 \pm 5.0$ & $26.2 \pm 6.6$ & 0.005 \\
\hline Right ventricular end-diastolic volume [mL] & $40.2 \pm 6.8$ & $43.6 \pm 7.5$ & 0.001 \\
\hline Right ventricular end-systolic area $\left[\mathrm{cm}^{2}\right]$ & $12.0 \pm 1.6$ & $13.2 \pm 2.2$ & 0.003 \\
\hline Right ventricular end-diastolic area $\left[\mathrm{cm}^{2}\right]$ & $21 \pm 2.8$ & $19.2 \pm 2.4$ & 0.03 \\
\hline Right ventricular fractional area change [\%] & $38.8 \pm 3.9$ & $32.5 \pm 5.5$ & $<0.001$ \\
\hline Tricuspid annular plane systolic excursion [mm] & $18.9 \pm 1.2$ & $12.8 \pm 1.9$ & $<0.001$ \\
\hline Inferior vena cava diameter $[\mathrm{mm}]$ & $15.6 \pm 1.7$ & $18.7 \pm 2.5$ & 0.001 \\
\hline Inferior vena cava collapse with inspiration [\%] & $40.8 \pm 17$ & $32.8 \pm 17$ & 0.004 \\
\hline
\end{tabular}

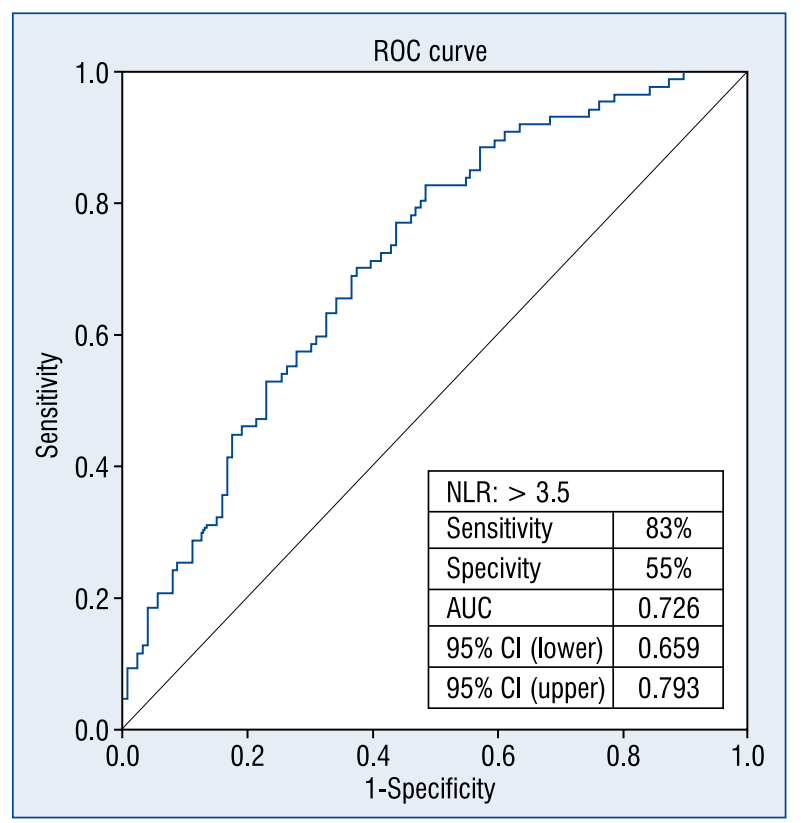

Figure 1. Characteristic operating curve (ROC) of neutrophil to lymphocyte ratio (NLR) for predicting right ventricular dysfunction.

can worsen ischemia and lead infarct expansion, as well [13-17].

Several investigators reported that increased number of circulating neutrophils was independently related to risk of heart failure and mortality in long-term following MI [18, 19]. In the other way, lymphocytopenia is a common finding secondary to increased corticosteroid levels induced by stress of coronary event [20]. Lymphocytopenia can also be found in non-cardiac patients with severe inflammation secondary to lymphocyte apoptosis [21]. Studies reported that lymphocytopenia was independently associated with mechanical complications and mortality in patients with acute STEMI $[22,23]$. The combination of these two variables which is the ratio of neutrophils over lymphocytes reflects the balance between the neutrophil and lymphocyte levels is the basis for this study [24]. In the present study, it was found as a main finding that RVD was significantly associated with neutrophil and lymphocyte count, and the NLR.

The NLR has been evaluated in coronary artery disease and acute coronary syndromes [25-27]. Kaya et al. [28] evaluated the role of the NLR in patients with STEMI undergoing PCI and found that NLR is an independent predictor of both inhospital and long-term adverse outcomes. Arbel et al. [29] showed that STEMI patients with high NLR had lower ejection fraction and more complications during their index hospitalization. Also, Akpek et al. [7] showed that NLR is an independently associated with the development of no-reflow phenomenon.

Another main finding, made by the authors is that time duration from symptom onset to PCI has an independent predictor of RVD. It meant that the 
Table 4. Univariate and multivariate regression analysis for prediction of right ventricular dysfunction.

\begin{tabular}{|c|c|c|c|c|c|c|}
\hline \multirow[t]{2}{*}{ Variable } & \multicolumn{3}{|c|}{ Univariate } & \multicolumn{3}{|c|}{ Multivariate } \\
\hline & $\begin{array}{l}\text { Unadjusted } \\
\text { odds ratio }\end{array}$ & $\begin{array}{c}95 \% \\
\text { confidence } \\
\text { interval }\end{array}$ & $\mathbf{P}$ & $\begin{array}{l}\text { Adjusted } \\
\text { odds ratio }\end{array}$ & $\begin{array}{c}95 \% \\
\text { confidence } \\
\text { interval }\end{array}$ & $\mathbf{P}$ \\
\hline Neutrophil/lymphocyte ratio & 1.490 & $1.260-1.820$ & $<0.001$ & 1.550 & $1.285-1.750$ & $<0.001$ \\
\hline Glomerular filtration rate & 0.975 & $0.912-1.025$ & 0.312 & & & \\
\hline Time from symptoms onset to $\mathrm{PCl}$ & 1.375 & $1.083-1.820$ & 0.007 & 1.320 & $1.085-1.810$ & 0.008 \\
\hline Door to balloon time & 0.950 & $0.895-1.035$ & 0.130 & & & \\
\hline Glucose on admission & 1.005 & $0.995-1.013$ & 0.212 & & & \\
\hline Multivessel disease & 0.445 & $0.223-0.875$ & 0.020 & 0.440 & $0.235-0.824$ & 0.03 \\
\hline Coronary lesion location & 1.850 & $1.050-3.140$ & 0.027 & 1.800 & $1.150-3.250$ & 0.02 \\
\hline TIMI flow before PCI & 1.205 & $0.970-1.680$ & 0.092 & & & \\
\hline TIMI flow after PCI & 0.951 & $0.651-1.389$ & 0.800 & & & \\
\hline ST-elevation in lead V4R & 3.800 & $1.55-13.5$ & $<0.001$ & 2.700 & $1.825-9.255$ & $<0.001$ \\
\hline LVEF in admission & 0.795 & $0.709-1.027$ & 0.225 & & & \\
\hline
\end{tabular}

$\mathrm{PCl}$ - percutaneous coronary intervention; TIMI — thrombolysis in myocardial infarction; LVEF — left ventricular ejection fraction

patient applying earlier got more benefit from PCI which is in consistence with the literature [30] since the patients with RVD had more prolonged time duration compared to patients without RVD.

Neutropil to lymphocyte ratio is an universally available hematological marker which can be easily calculated. The results of the present study suggest that this diagnostic test might be used in addition to other tests to predict RVD in patients with acute inferior STEMI.

\section{Limitations of the study}

The sample size was relatively small. Other inflammatory markers such as high sensitivity-C-reactive protein, myeloperoxidase or fibrinogen were not included. Evaluation of RV strain which might yield additional data on RV function in STEMI was not performed. Finally, some recovery in RV function might have occurred before echocardiographic examination was performed. However, this does not imply that the results might be erroneous, rather the results are still statistically significant despite some neutralizing effects of normal RV function on the predictor power of the NLR.

\section{Conclusions}

Neutrophil to lymphocyte ratio was an independent predictor of RVD in patients with inferior STEMI undergoing primary PCI.

Conflict of interest: None declared

\section{References}

1. Andersen HR, Falk E, Nielsen D. Right ventricular infarction: Frequency, size and topography in coronary heart disease: A prospective study comprising 107 consecutive autopsies from a coronary care unit. J Am Coll Cardiol, 1987; 10: 1223-1232.

2. Goldstein JA. Pathophysiology and management of right heart ischemia. J Am Coll Cardiol, 2002; 40: 841-853.

3. Zehender M, Kasper W, Kauder E et al. Right ventricular infarction as an independent predictor of prognosis after acute inferior myocardial infarction. N Engl J Med, 1993; 328: 981-988.

4. Mehta SR, Eikelboom JW, Natarajan MK et al. Impact of right ventricular involvement on mortality and morbidity in patients with inferior myocardial infarction. J Am Coll Cardiol, 2001; 37: $37-43$.

5. Kaya MG, Uyarel H, Akpek M et al. Prognostic value of uric acid in patients with ST-elevated myocardial infarction undergoing primary coronary intervention. Am J Cardiol, 2012; 109: 486-491.

6. Akpek M, Kaya MG, Uyarel $\mathrm{H}$ et al. The association of serum uric acid levels on coronary flow in patients with STEMI undergoing primary PCI. Atherosclerosis, 2011; 219: 334-341.

7. Akpek M, Kaya MG, Lam YY et al. Relation of neutrophil/lymphocyte ratio to coronary flow to in-hospital major adverse cardiac events in patients with ST-elevated myocardial infarction undergoing primary coronary intervention. Am J Cardiol, 2012; 110: 621-627.

8. The Thrombolysis in Myocardial Infarction (TIMI) trial. Phase I findings. TIMI Study Group. N Engl J Med, 1985; 312: 932-936.

9. Windecker S, Kolh P, Alfonso et al. 2014 ESC/EACTS Guidelines on myocardial revascularization: The Task Force on Myocardial Revascularization of the European Society of Cardiology (ESC) and the European Association for Cardio-Thoracic Surgery (EACTS)Developed with the special contribution of the European Association of Percutaneous Cardiovascular Interventions (EAPCI). Eur Heart J, 2014; 35: 2541-2619. 
10. Lang RM, Badano LP, Mor-Avi V et al. Recommendations for cardiac chamber quantification by echocardiography in adults: An update from the American Society of Echocardiography and the European Association of Cardiovascular Imaging. J Am Soc Echocardiogr, 2015; 28: 1-39 e14.

11. Mann DL, Young JB. Basic mechanisms in congestive heart failure. Recognizing the role of proinflammatory cytokines. Chest, 1994; 105: 897-904.

12. Torre-Amione G, Kapadia S, Benedict C, Oral H, Young JB, Mann DL. Proinflammatory cytokine levels in patients with depressed left ventricular ejection fraction: A report from the Studies of Left Ventricular Dysfunction (SOLVD). J Am Coll Cardiol, 1996; 27: 1201-1206.

13. Reichlin T, Socrates T, Egli P et al. Use of myeloperoxidase for risk stratification in acute heart failure. Clin Chem, 2010; 56: 944-951.

14. Baldus S, Heeschen C, Meinertz T et al. Myeloperoxidase serum levels predict risk in patients with acute coronary syndromes. Circulation, 2003; 108: 1440-1445.

15. Mehta J, Dinerman J, Mehta P et al. Neutrophil function in ischemic heart disease. Circulation, 1989; 79: 549-556.

16. Tousoulis D, Antoniades C, Koumallos N, Stefanadis C. Pro-inflammatory cytokines in acute coronary syndromes: From bench to bedside. Cytokine Growth Factor Rev, 2006; 17: 225-233.

17. Madjid M, Awan I, Willerson JT, Casscells SW. Leukocyte count and coronary heart disease: Implications for risk assessment. J Am Coll Cardiol, 2004; 44: 1945-1956.

18. Arruda-Olson AM, Reeder GS, Bell MR, Weston SA, Roger VL. Neutrophilia predicts death and heart failure after myocardial infarction: A community-based study. Circ Cardiovasc, Qual Outcomes, 2009; 2: 656-662.

19. Kyne L, Hausdorff JM, Knight E, Dukas L, Azhar G, Wei JY. Neutrophilia and congestive heart failure after acute myocardial infarction. Am Heart J, 2000; 139: 94-100.

20. Onsrud M, Thorsby E. Influence of in vivo hydrocortisone on some human blood lymphocyte subpopulations. I. Effect on natural killer cell activity. Scand J Immunol, 1981; 13: 573-579 .

21. Hotchkiss RS, Karl IE. The pathophysiology and treatment of sepsis. N Engl J Med, 2003; 348: 138-150.

22. Widmer A, Linka AZ, Attenhofer Jost CH et al. Mechanical complications after myocardial infarction reliably predicted using $\mathrm{C}$-reactive protein levels and lymphocytopenia. Cardiology, 2003; 99: 25-31.

23. Dragu R, Khoury S, Zuckerman R et al. Predictive value of white blood cell subtypes for long-term outcome following myocardial infarction. Atherosclerosis, 2008; 196: 405-412.

24. Horne BD, Anderson JL, John JM et al. Which white blood cell subtypes predict increased cardiovascular risk? J Am Coll Cardiol, 2005; 45: 1638-1643.

25. Kalay N, Dogdu O, Koc F et al. Hematologic parameters and angiographic progression of coronary atherosclerosis. Angiology, 2012; 63: 213-217.

26. Papa A, Emdin M, Passino C, Michelassi C, Battaglia D, Cocci F. Predictive value of elevated neutrophil-lymphocyte ratio on cardiac mortality in patients with stable coronary artery disease. Clin Chim Acta, 2008; 395: 27-31.

27. Duffy BK, Gurm HS, Rajagopal V, Gupta R, Ellis SG, Bhatt DL. Usefulness of an elevated neutrophil to lymphocyte ratio in predicting long-term mortality after percutaneous coronary intervention. Am J Cardiol, 2006; 97: 993-996.

28. Kaya MG, Akpek M, Lam YY et al. Prognostic value of neutrophil/lymphocyte ratio in patients with ST-elevated myocardial infarction undergoing primary coronary intervention: A prospective, multicenter study. Int J Cardiol, 2013; 168: 1154-1159.

29. Arbel Y, Shacham Y, Ziv-Baran T et al. Higher neutrophil/lymphocyte ratio is related to lower ejection fraction and higher longterm all-cause mortality in ST-elevation myocardial infarction patients. Can J Cardiol, 2014; 30: 1177-1182.

30. Widimsky P, Budesinsky T, Vorac D et al. Long distance transport for primary angioplasty vs immediate thrombolysis in acute myocardial infarction. Final results of the randomized national multicentre trial: PRAGUE-2. Eur Heart J, 2003; 24: 94-104. 